\title{
ОБ УПОРЯДОЧЕННОМ ВРАЩЕНИИ КРОВИ В АРТЕРИЯХ
}

\author{
*Нефёдов А.Ю., Асфандияров Р.И., Светайло Л.Ю., Канаев С.П., Расстригин С.Н. \\ Центр мануальной терапии МЗ РФ г. Москва, РФ; \\ Кафедра анатомии человека АГМА, г. Астрахань, РФ
}

Если хочешь узнать тайну движсения секундной стрелки, загляни внутрь механизма часов.

Итальянская пословица.

\section{Причина внешних явлений есть результат внутреннего двиюсения и уст- ройства}

Платон. Диалоги.

$\mathrm{X}$ арактерная особенность кровотока по магистральным артериям головы заключается в том, что мозг очень чувствителен к ишемии и моментально реагирует даже на кратковременную его остановку. Такая постоянная высококачественная перфузия обеспечивается несколькими механизмами: во-первых, упорядоченным вращением потока крови вообще, во-вторых, некоторыми анатомическими особенностями сонных и позвоночных артерий, в третьих, ауторегуляцией мозгового кровообращения.

Теории ламинарного, турбулентного и иного движения крови по сосудам не выдерживают критики по многим причинам. Ocтановимся только на том, что поддерживать ламинарный поток в местах бифуркации (переменные диаметры) невозможно. Невозможен ламинарный поток и при движении жидкости с переменным (пульсирующим) давлением и переменной линейной скоростью, ведь одно из условий существования ламинарного потока - это равномерное или равноускоренное движение всех участков потока, что также невозможно при пульсирующем потоке в трубе переменного диаметра и мягкими стенками. Важным обстоятельством является ещё и то, что при лами*e-mail: doppler@rambler.ru нарном или турбулентном потоке, или при их любом сочетании, невозможно было бы обезопасить форменные элементы крови от механических перегрузок, например, при столкновение со стенкой. Единственным способом продвижения крови по сосудам, при котором возможно обеспечить циркуляцию одним насосом средней мощности (сердцем) при гигантской площади и объеме сосудистого русла, не повреждая форменные элементы, является упорядоченное вращение крови в сосудах в сочетании с активным перистальтикоподобным движением сосудов, поддерживающим это вращение и продвижение крови по артериям. Исследование на тканевом и клеточном уровне подтверждают это. Имеется целая система обеспечения закрученных потоков крови [1]. Строение стенок сосудов таково, что они, подобно нарезке оружейного ствола, обеспечивают постоянное поддержание вращения потока крови до капилляров (Рис 1), в отличии от ружейного ствола, сосуд поддерживает вращение кровотока активно.

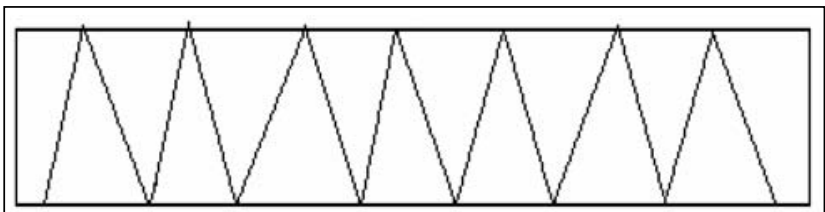

Рис 1. Схема спиральных трабекул в стенке артерии 


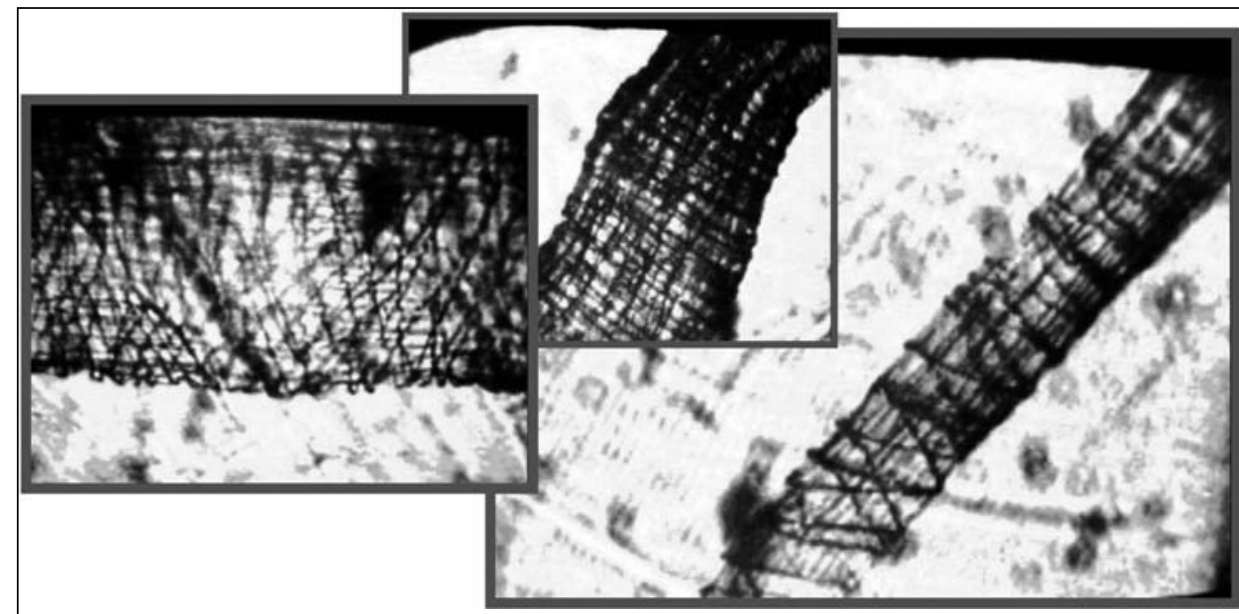

Рис 2. Артериолы. Видны спиральные структуры системы обеспечения вращения крови - "нарезка".

Препараты и импрегнация по методу профессора Р.И. Асфандиярова. треугольное (Рис 3В) отверстие аортального клапана также способствует поддержанию вращения крови, далее вращение поддерживается артериальными стенками. Согласованность работы артерий и сердца так высока, что кровоток осуществляется почти без трения, более того, каждый по-

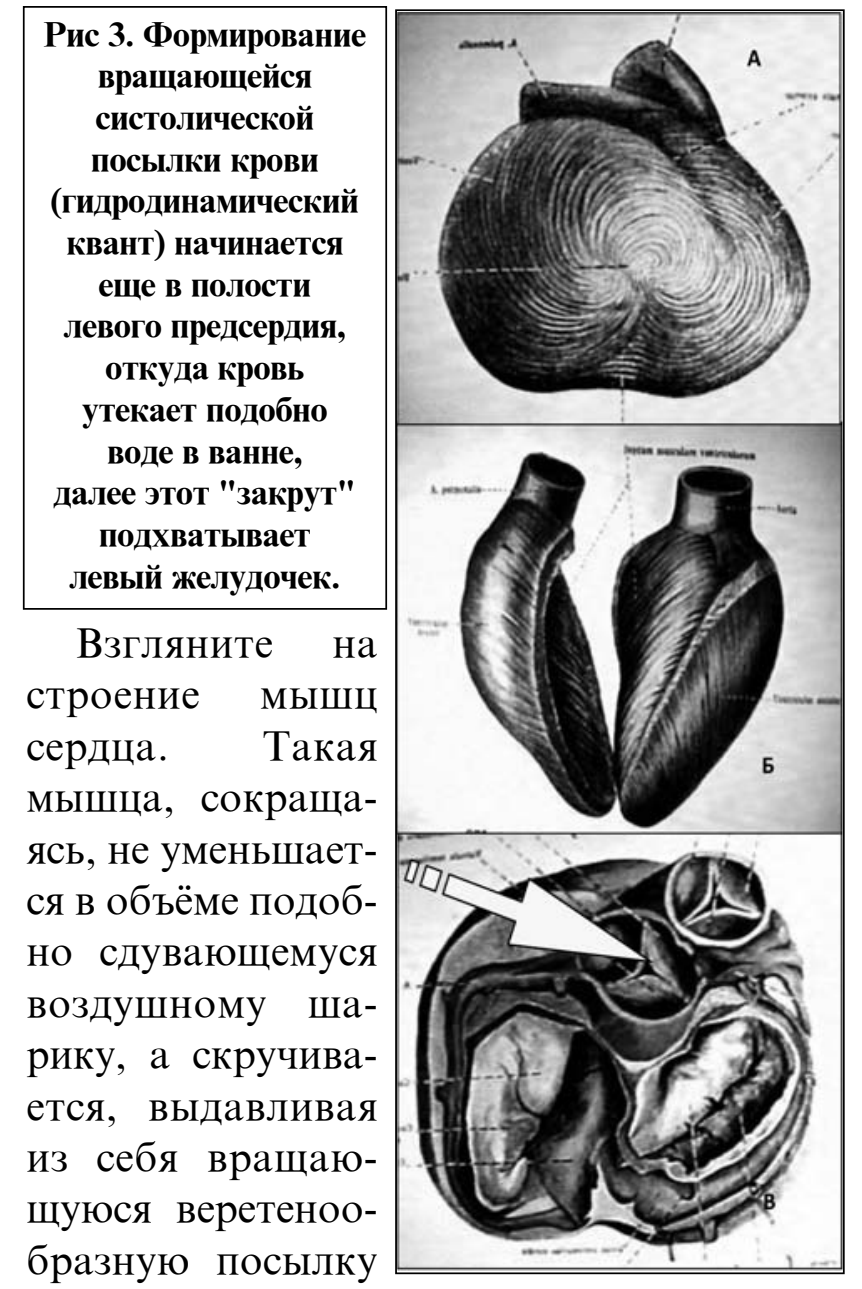
крови (Рис 3 А, Б, Атлас Воробьева В.С.).

Феномен верхушечного толчка обусловлен тем, что в систолу сердце скручивается, изгибается и верхушка его ударяет в грудную стенку.
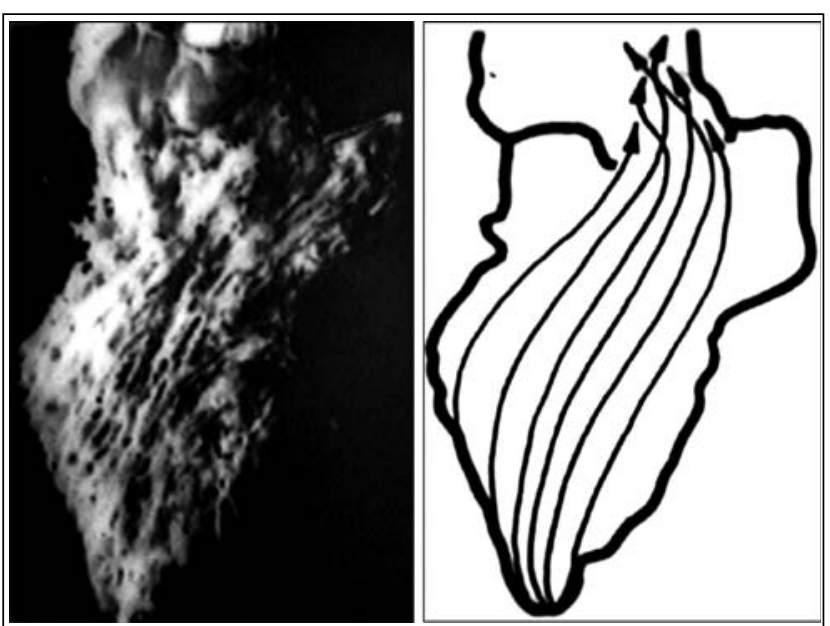

Рис 4. Слепок левого желудочка сердца, на схеме рядом расположение трабекул и складок для формирования закрученного потока. Препарат и методика профессора Асфандиярова Р.И. следующий сосудистый сегмент передает по симпатическим структурам информацию о приближении систолической посылки и артерии «раскручиваются» навстречу нарастающему потоку и «скручиваются» при его убывании в диастолу. Сосудистая стенка чутко приспосабливается к потоку крови, подобный механизм описан при движении дельфина в воде, когда поверхность тела этого млекопитающего приспосабливается к окружающей среде, из-за чего дельфины могут передвигаться с большой скоростью, оставляя за собой минимальные возмущения в толще воды. Своео- 
бразная вращательная перистальтика, обеспечиваемая взаимодействием сосудистой и нервной систем, позволяет экономить кинетическую энергию вращения потока, благодаря чему, собственно, и возможно кровообращение.

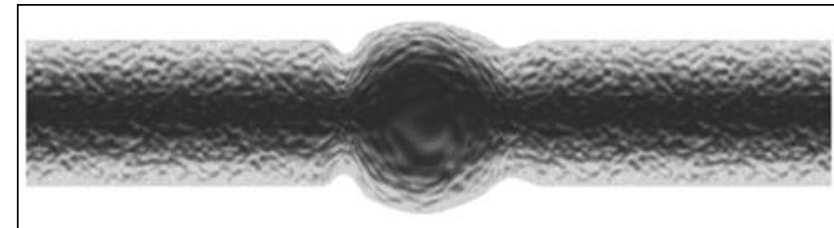

Рис. 5. Вращение крови в сосудах (продолговатый срез).

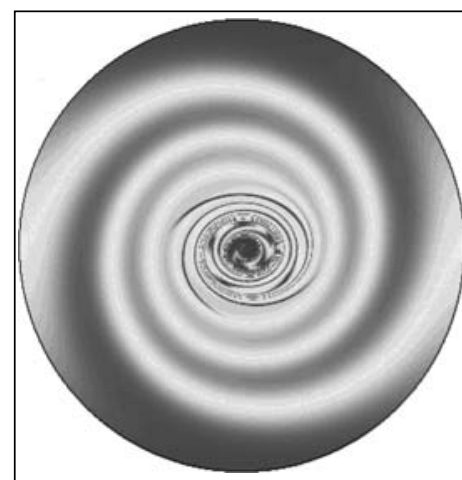

Рис. 6. Вращение крови в сосудах (поперечный срез).

Вращение крови из-за гидродинамического давления (согласно закономерностям, описанным А. Эй н ш т ей н о м ) формирует структуру потока, при этом плазма движется, быстро вращаясь, по периферии диаметра, а форменные элементы выдавливаются внутрь потока, где испытывают меньшие гидродинамические и механические нагрузки (Рис 5-6).

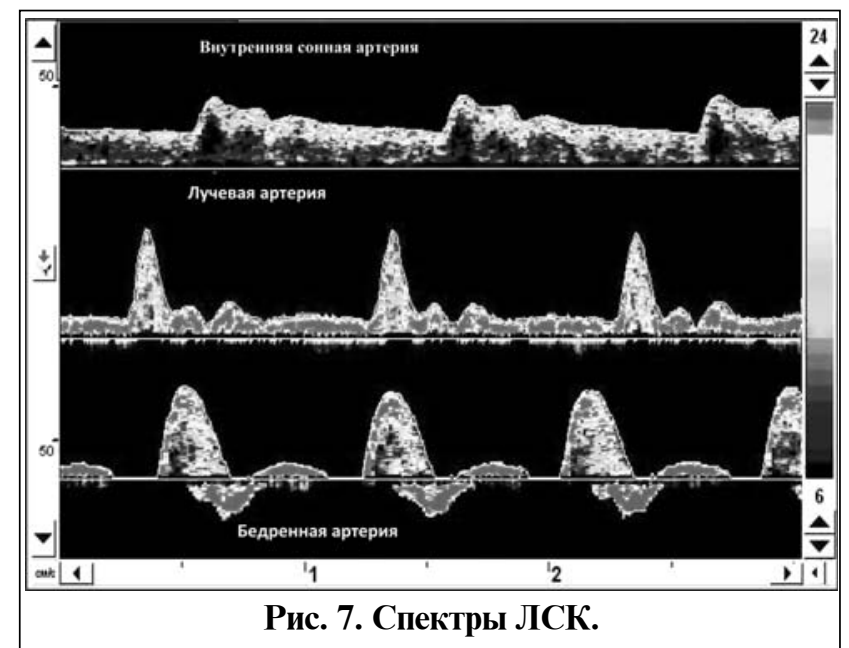

Стабильность такого потока намного выше ламинарного. Попробуйте нести на подносе не вращающийся детский волчок сложно, а если его раскрутить, то никаких проблем. Так же трудно даже представить себе, как бы осуществлялась доставки крови при выполнении движений, например рукой, согнутой в локте со сжатыми пальцами, какое количество изгибов необходимо было бы преодолевать потоку и какими механизмами обеспечивалась бы ламинарность? Закрученный потока универсален и стабилен независимо от положения конечности или органа, и подтверждается морфологически.

Вращение крови в артериях - механизм универсальный. Но мы уже говорили об особенностях именно мозгового кровообращения и об особом отношении клеток мозга к качеству кровотока. Мало того, что мозг не может жить более 5-ти минут без кислорода, для его нормальной функции необходимо, чтобы кровоток, ритмично пульсируя, не останавливался ни на секунду. ЛСК в сосудах мозга в норме всегда больше 0 , т.е. движение крови может замедляться и ускоряться, но не останавливаться и не двигаться обратно. На рисунках спектров ЛСК (Рис 7) хорошо видно, что кривая ЛСК по МАГ отличается от спектра ЛСК сосудов конечностей тем, что в любой момент времени (и в систолу, и в диастолу) ее спектр выше изолинии. Кровоток в артериях конечностей может не только останавливаться, но в диастолу может быть обратным.

В отличии от всех остальных органов и систем мозг заключен в нерастяжимый, жесткий череп, поэтому соотношение вещества мозга, притока артериальной крови, оттока 
венозной и количества ликвора строго определено, и циркуляция этих жидкостей строго взаимно детерминирована. Но кроме дополнительного объема жидкости, кровь несет в себе еще механическую энергию, способную вызвать гидродинамический удар, воздействие которого на мозг, ощущается как пульсирующая головная боль, например, при мигрени. Особое анатомическое строение артериальных магистралей, питающих мозг, и их взаимодействие с костями шейного отдела позвоночника и костями черепа позволяет без торможения систолической посылки демпфировать (сглаживать) кровоток. Особенностью всех магистральных артерий, питающих мозг, является их отхождение от материнского сосуда под прямым углом (Рис 8), правая позвоночная артерия (а. вертебралис дехтра) - исключение, она чаще отходит под углом 700-600. И об этом неслучайном явлении немного ниже.

Интракраниальные артерии, также как сонные и позвоночные, отходят от основного ствола под прямым углом, что характерно для большинства интрацеребральных артерий вплоть до капилляров.

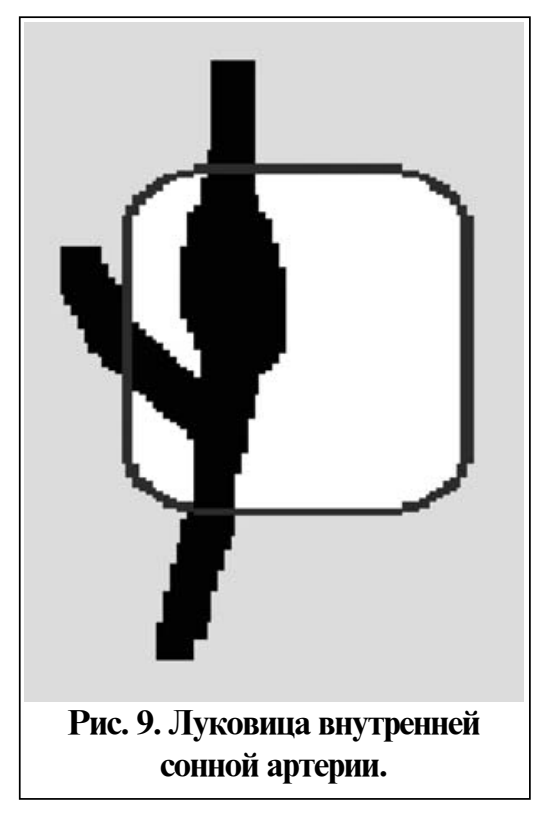

К гидродинамически активным сегментам относятся луковицы внутренних сонных артерий (BCA) булбус саротис интерна. Эти м ы ш е ч н ы е у толщения, расположен ные над бифуркацией общей сонной артерии (ОСА), дожимают кровь в диастолу, не давая ей двигаться назад (Рис 9).

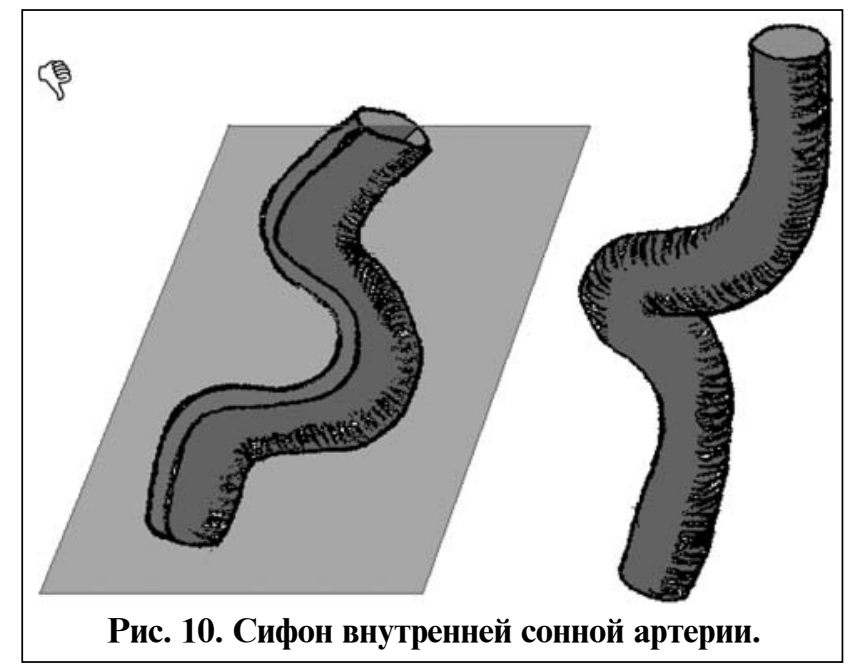

С-образный изгиб сифона ВСА в толще височной кости (сифон) частично гасит гидродинамический удар (часть энергии передается венозной крови кавернозного синуса, осуществляя активное откачивание венозной крови из передней черепной ямки). Сифон имеет особенную форму: изгиб находится не в одной плоскости, а несколько развернут (Рис 10). Стенки артерии плотно сращены с костным каналом в височной кости и не могут активно поддерживать движение крови. В сифоне ВСА поток, теряя ударную силу, наращивает энергию вращения за счет формы, подобно бобслейным саням, движущимся в ледяном желобе.

O с о бен н о подробно необходимо остановиться на строении и функции самой уникальной ангиосистемы - вертебрально-бази лярной (ВБС). При всей своей симметричности в схемах и атласах ВБС а $б$ с о л ю т н о асимметрична, и анатомичес-

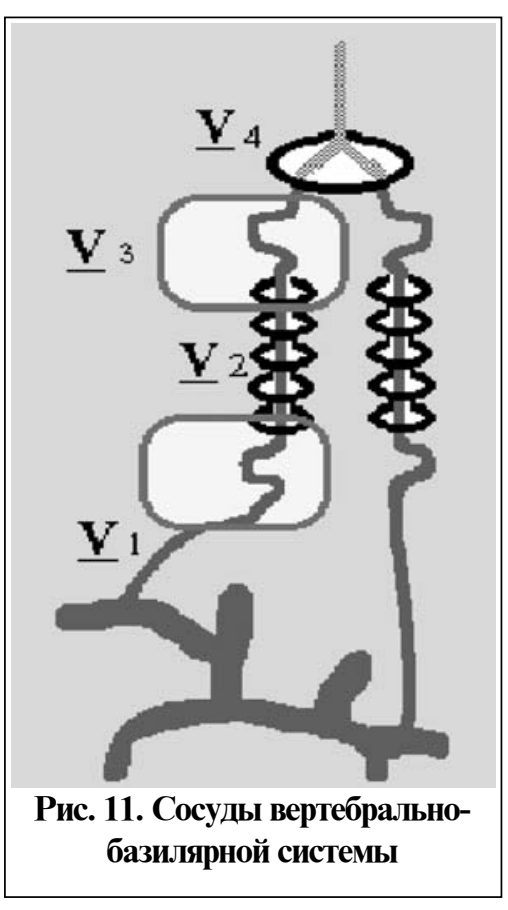


ки, и функционально (Рис 11). Правая артерия всегда уже, чем левая и отходит под острым углом, путь систолической посылки крови по правой позвоночной артерии (ПрПА) всегда длиннее уже за счет безымянной артерии (а. анонима). Асимметрия диаметров ПА в норме не превышает 2530\%. Изгиб ПА перед входом в одноименный канал (сегмент В1- от подключичной артерии до входа в канал ПА) и изгиб после выхода из него (ВЗсегмент) играют роль демпфера как и сифон ВСА. Изгиб ПА в сегменте В3 выполняет роль запасной длины при повороте и наклоне головы в сторону. Необходимо уточнить, что при повороте головы в сторону, вращение головы и шеи происходит не вокруг вертикальной оси, проходящей через ось позвоночника, а вокруг оси, проходящей через канал ПА. Иначе говоря, при повороте головы в сторону (например, вправо), поворот производится вокруг правой ПА (ПрПА), левая ПА (ЛеПА) при этом, выпрямляется в сегменте В3. В норме, при ротации головы в сторону, снижение кровотока по ПА, противоположной стороне поворота, составляет не более $15 \%$, или не изменяется (0$15 \%)$.

Столь незначительные изменения кровотока при ротации головы возможны только при правильном распределении всей суммы движений в шейном и шейногрудном отделах позвоночника (ШОП, Ш-ГОП), когда нет функциональных блокад (ФБ) позвоночных двигательных сегментов - ПДС. ПДС - это два позвонка с дугоотростчатыми суставами и межпозвоночный диск (МПД) между ними. Если же поворот головы осуществляется в условиях ФБ ПДС ШОП, то гипоциркуляция может составлять от 15\%, до пол-ного его исчезновения, так как при блокаде одних ПДС, в других движение превышает физиологический объем, особенно это, касается краниовертебрального перехода (сег- мент С0-C1). Блок в С0-С1 ведет к дисциркуляции в ВБС. Особенностью строения ВБС являются тонкие косо расположенных соединительнотканные тяжи внутри костных колец, образующих канал ПА (Рис 12).

Благодаря тяжам, артерия не может значительно растягиваться или суживаться в этих сегментах, между кольцами артерия свободна. Активная перистальтика систолической посылки крови оказ ы в е тся

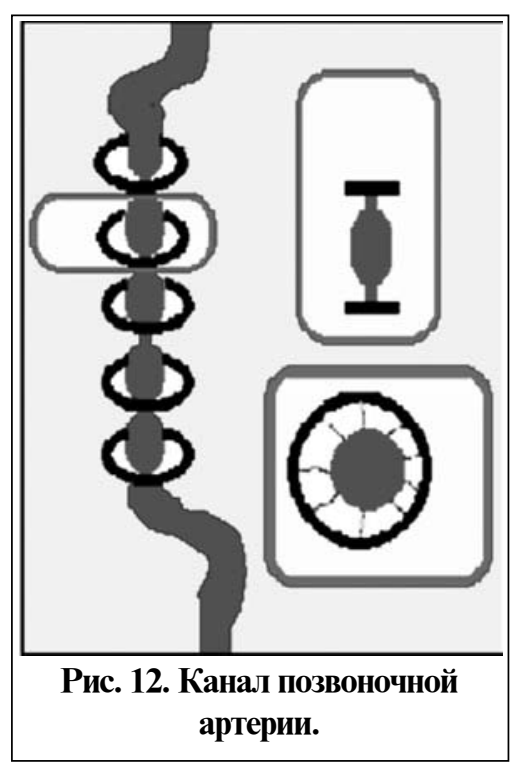
эффективной в такой конструкции, а вот обратный откат крови невозможен. Но при развитии подвывихов (подвывих Люшка) в ПДС шейного отдела позвоночника, связки изменяют длину и развитие спастических нарушений становится возможным.

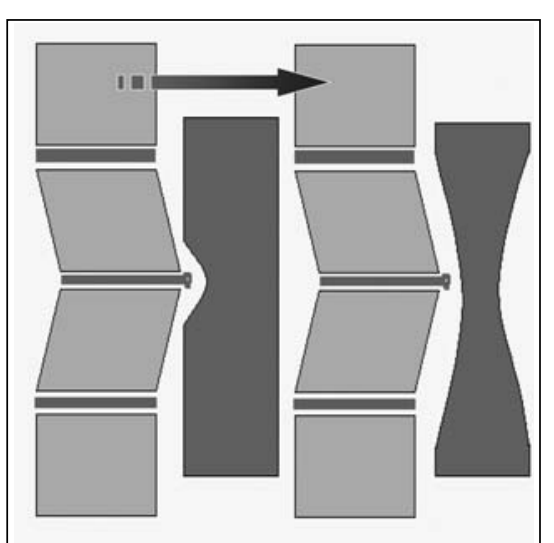

Рис. 13. Развития гиперсензитивного участка сосудистой стенки.
А р те ри и имеют симпатические образования на поверхности, поэтому короткое, но сильное механическое возд е й с т в и е (травма), и слабое, но длительное воздействие

на стенку артерии, приводит, сначала к развитию гиперсензитивного участка сосудистой стенки (Рис 13), поэтому нор- 
мальная посылка крови вызывает парадоксальную реакцию: вместо раскрытия ПА реагирует временным, а затем и стойким спазмом. В данном участке артерии кровоток резко снижается из-за того, что коническая деформация сосуда имеет гидродинамические свойства стеноза, при котором большая часть крови отбрасывается назад, и потому, что прерывается сообщение между сегментами артерий и эстафета оповещения о приближающейся систолической посылке крови не срабатывает. Воздействие патологически напряженной шейной мышцы, грыжи МПД, приводит к развитию локальной неатеросклеротической, спондилогенной гипоциркуляции в ПА.

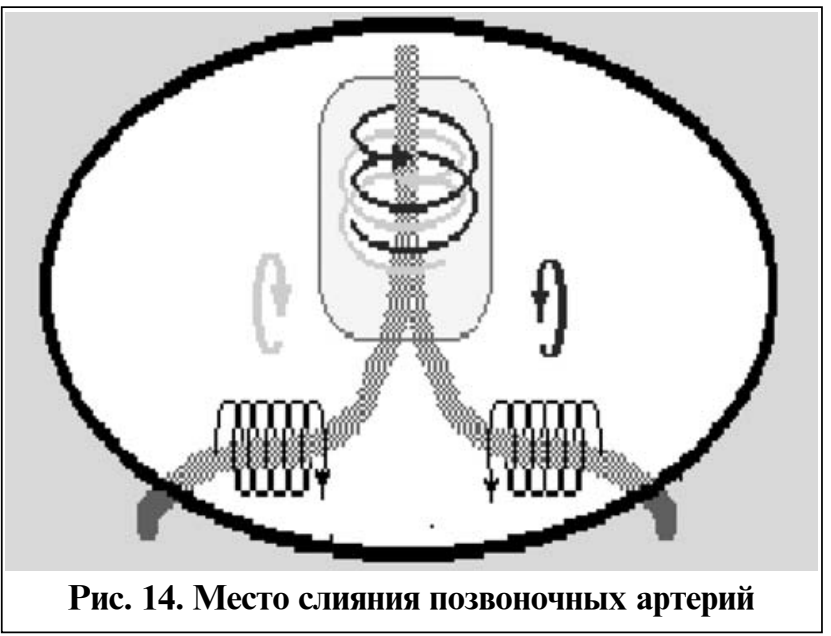

Место слияния ПА имеет особенности строения (Рис 14),так как здесь, во-первых, встречаются два потока крови, вращающиеся в противоположные стороны, а, во-вторых, систолический максимум сдвинут по фазе, так как кровь по правой ПА всегда запаздывает из-за более длинного пути и меньшего диаметра. Однако, строение места слияния ПА позволяет разрешить эти проблемы (Рис 15). При вливании в основную артерию (ОснА) потоки левой и правой ПА закручиваются друг за друга (Рис 14), а поочередное поступление крови из ПА увеличивает стабильность кровотока в ОснА.

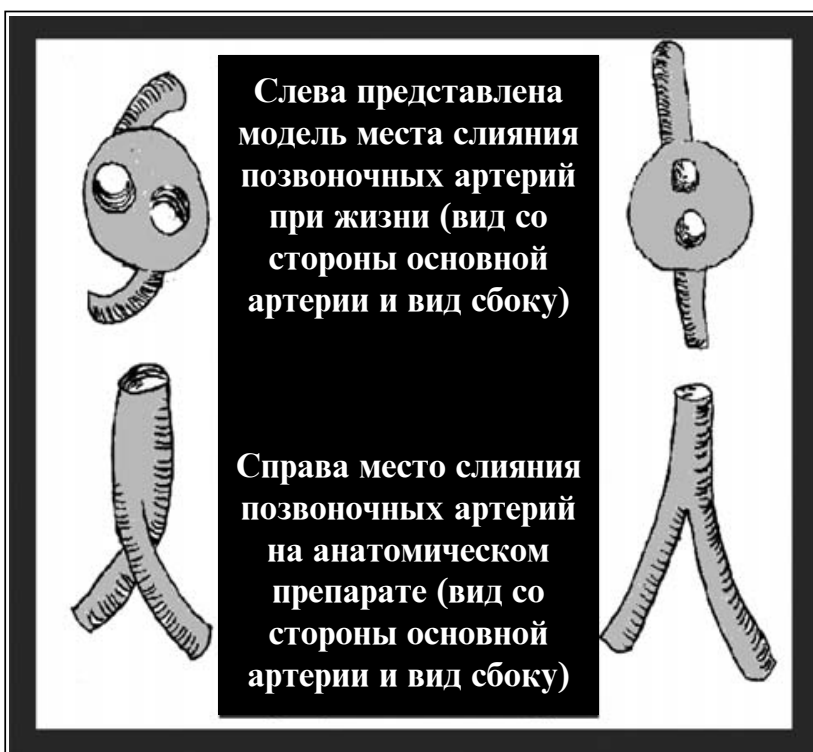

Рис. 15. Модель места слияния позвоночных артерий

При нарушении формы и функции ПА при шейном остеохондрозе и интравазальном поражении эта сложная гемодинамика нарушается, проявляясь ишемией в ВБС.

Знание анатомо-функциональных особенностей сосудистой системы важно в клинике мануальной терапии (МТ) и неврологии, так как наличие, например, гипоплазии ПА (ГППА) может быть разрешающим фактором развития вертебрально-базилярной недостаточности, и определять тактику ведения больного мануальным терапевтом или неврологом.

Важность этого знания становится еще более понятной после того как стало известно, что соединение азота (НО) является фактором быстрого раскрытия просвета нормального сосуда при прохождении по нему нормальной систолической посылки крови. НО крайне быстро разрушается в тканях, что совпадает с повышением сосудистого тонуса после прохождения систолического кванта крови. Нобелевская комиссия Каролинского медикохирургического института в Стокгольме назвала лауреатами Нобелевской премии в области физиологии и медицины за 1998 год трех американских ученых - Роберта Фёрчготта, Луиса Игнарро и Ферида Мюрада (Robert F. Furchgott, Louis J. 
Ignarro, Ferid Murad). Они удостоены Нобелевской премии за открытие "окиси азота как сигнальной молекулы в кардиоваскулярной системе". Факт образования газа в клетке, который, минуя мембраны, может управлять функциями других клеток, признан неизвестным до сих пор новым принципом подачи сигналов в живых организ- ную скорость потока вдоль сосуда, а скорость вращения потока, при этом ближняя к датчику часть потока движется в одну сторону, а удаленная от него - в противоположную. Очевидно, что движение крови в нормальном сосуде в противоположных направлениях одновременно невозможно.

Таким образом, если при каком-либо мах (И.ВЕКСЛЕР, Бостон, http://www.vestnik.com/ issues/98/1124/koi-/vexler.htm).

В момент проведения манипуляции на ШОП запускается механизм НОактивации артерий, длительно находящихся в стадии спазма, и, одновременно, восстанавливается подвижность в ШОП, обеспечивая свободу реагирования ПА. Вот чем объясня-

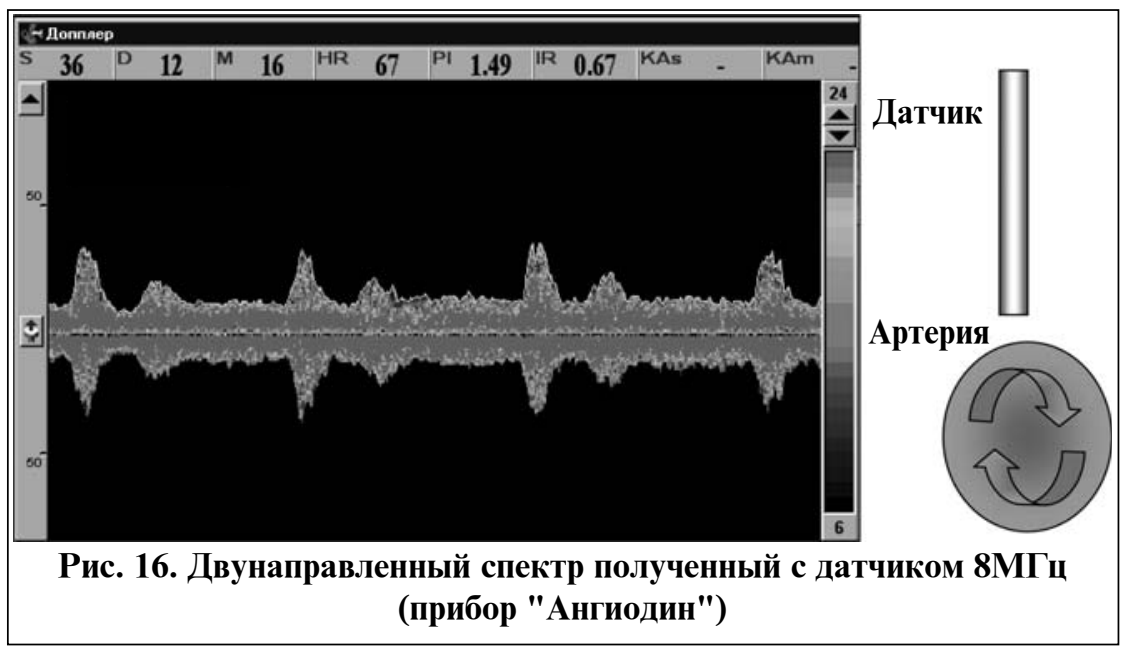
ется короткая но бурная реакция ПА на манипуляцию, впервые описанная в ЦМТ МЗ РФ [2].

Новые подходы и взгляды на привычные, устоявшиеся понятия всегда встречают сопротивление консервативного большинства, требующего доказательств. Прежде, чем мы продолжим изложение диагностических возможностей допплерографии в клинике мануальной терапии, приведем одно простое доказательство вращения кровотока в артерии.

Известна формула закона Допплера: $\boldsymbol{F} \boldsymbol{d}=\mathbf{2} \boldsymbol{x} \boldsymbol{F o x} \boldsymbol{V} \boldsymbol{x} \boldsymbol{c o s} \boldsymbol{a}$, где альфа - угол между направлением потока и осью датчика. Также известно, что $\cos 90^{\circ}=0$, т.о. если датчик поставить перпендикулярно к артерии (потоку крови), то $\boldsymbol{F} \boldsymbol{d}=\mathbf{2} \boldsymbol{x} \boldsymbol{F o x} \boldsymbol{V} \boldsymbol{x} \boldsymbol{0}=\mathbf{0}$. Однако, установив датчик 8МГц прибора «Ангиодин», производства Российской фирмы «БИОСС», перпендикулярно даже к лучевой артерии, мы получаем двунаправленный спектр (Рис 16), что объясняется тем, что датчик фиксирует не линей-

патологическом процессе произойдет десимпатизация какого-либо участка артерии, или наоборот возникнет ситуация симпатического перевозбуждения на каком-то участке сосуда, то в дистальных отделах возможно нарушение кровотока.

Прекрасными моделями для такого процесса являются синдром передней лестничной мышцы (скаленус синдром) и синдром грушевидной мышцы (пириформис синдром).

Синдромом передней лестничной мышцы (СПЛМ), или скаленус синдромом называют заболевание, характеризующееся раздражением и частичной компрессией подключичной артерии и нервов плечевого сплетения в щели, между передней (ПЛМ) и средней лестничной мышцами (Рис 17 А и Б).

Причин для развития скаленус синдрома существует много, но при любом генезе развивается он вследствие длительного патологического напряжения передней лестничной мышцы. На первый взгляд кажется, что при допплерографии ценным было бы исследование именно подключичной артерии, но это 

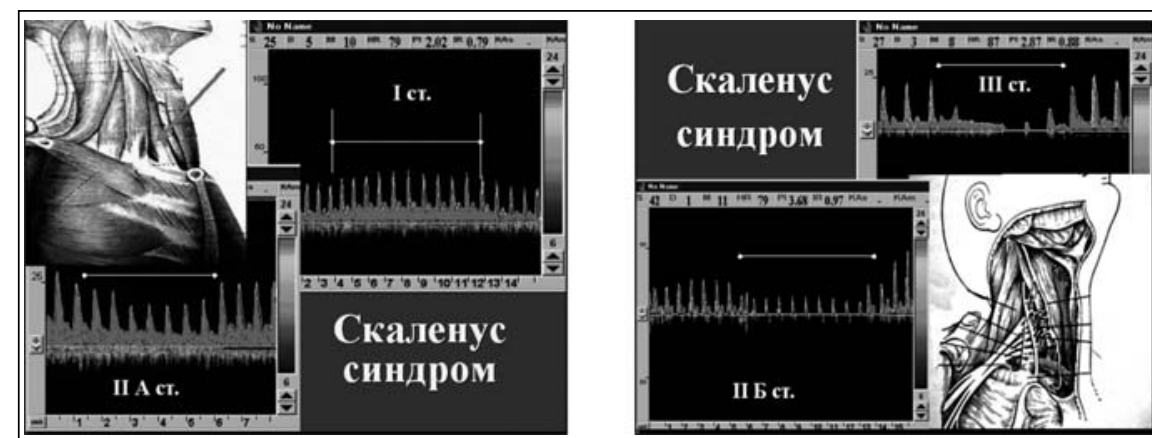

Рис 17. А 1-я и 2-я "А" степени, Б - 2-я "Б" и 3-я степень СПЛМ кнаружи, голова «прямо», шея и руки максимально расслаблены. Порядок проведения исследования таков: получают четкий сигнал от лучевой артерии, затем просят больного максимально повернуть голову в противоположную локации сторону (при локации не так. Подключичная артерия очень мощ- левой лучевой артерии голову поворачиваная и компрессия ее при скаленус синдроме, конечно, имеет место, но не такая, чтобы её можно было определить по изменениям ЛСК или спектров самой подключичной артерии (ПклА), конечно, это не касается случаев тяжелого течения скаленус синдрома. Изменения спектра на локтевой артерии определяются при скаленус синдроме в рамках обычной асимметрии и не могут
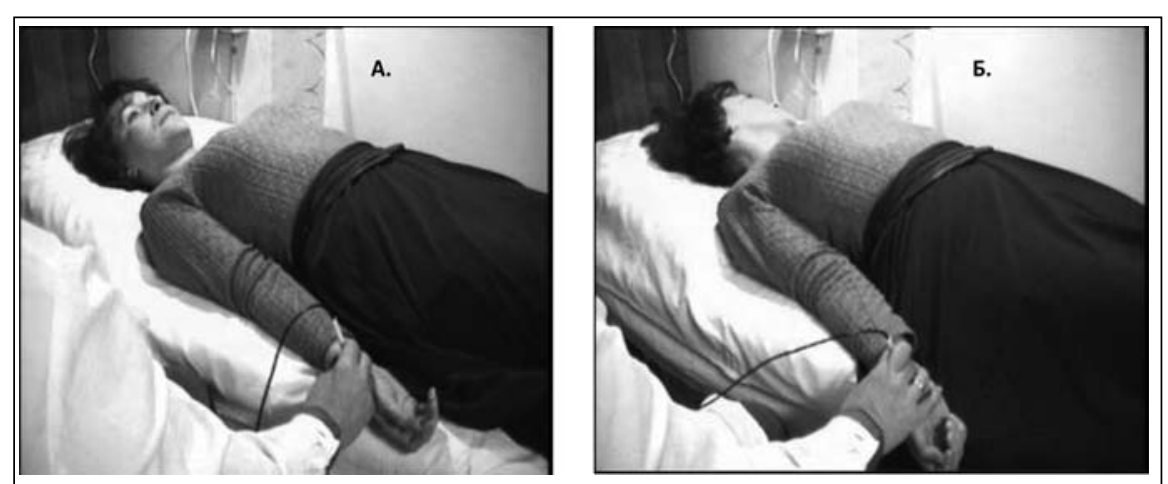

Рис. 18. Провокационная проба в диагностике скаленус синдрома

мен преходящей дисциркуляции в кисти в ния кровотока по лучевой артерии на уровне запястья четко регистрируют страдание ПклА. Важной составляющей скаленус синдрома является хроническая боль из-за постоянного раздражения вегетативных рецепторов, что приводит к нарушению вегетативного обеспечения, и, как следствия, нарушения циркуляции в дистальных отделах кисти. Важным моментом в диагностике скаленус синдрома является провокационная проба с поворотом головы в здоровую сторону, когда можно пальпировать напряженную ПЛМ. Эта же проба проводится при допплерографии, лоцируется лучевая артерия на стороне, противоположной повороту головы (голову поворачивают в сторону от исследуемой артерии (Рис 18 А и Б). Первая часть исследования проводится в стандартно: больной в положении лёжа на спине, руки вдоль тела, ладони развернуты вверх и виде нарастания диастолической составляющей без значительного изменения систолической составляющей - 1-я степень; снижение систолической составляющей, с сохранением диастолической - 2А степень, исчезновение диастолической составляющей, при сохранности абортивного кровотока в систолу - 2Б степень, и, наконец, скаленус синдром 3-й степени характеризуется полным прекращением кровотока по лучевой артерии при повороте головы (Рис 17). На этапе развернутой клиники скаленус синдрома отчетливы нарушения трофики (ломкость ногтей, бледность, сухость, часто мраморность кожи руки, особенно кисти), так же может определяться и снижение пульсации на лучевой артерии. Но известно, что скаленус синдром может быть не только самостоятельным заболеванием, гипертонус ПЛМ часто развивается в рамках 
других синдромов, например, при заднем шейном симпатическом синдроме, синдроме усталых плеч, дорсалгиях, плечелопаточном периартериите и т.п. При множестве спондилогенных и миофасциальных болевых синдромах выявление и лечение скаленус синдрома особенно актуально на ранних стадиях, что позволяет легко сделать методика УЗДГ БЦА и В. дится на удалении от непосредственного места конфликта. Перед проведением исследования микроциркуляции на первой фаланге I-го (иногда II-го) пальца стопы, проводится стандартное исследование АНК, включающее поэтажное манжетирование, если выявлены грубые асимметрии спектра.

Близость патофизиологических меха-

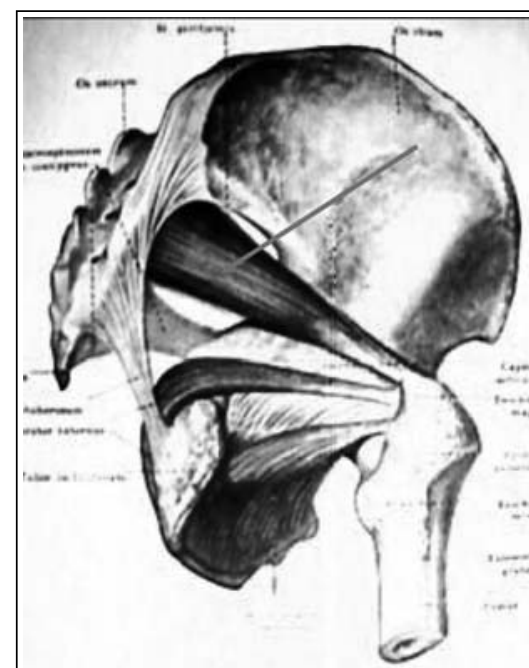

Рис. 19. Грушевидная мышца

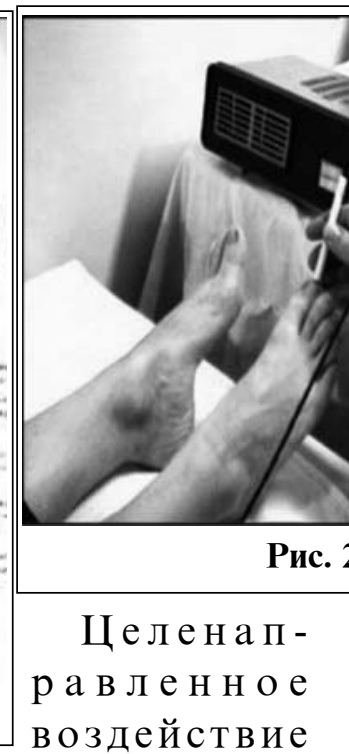
воздействие

на переднюю лестничную мышцу методами мануальной терапии (либо комплексом методов) приводит к регрессу симптоматики, исчезает феномен преходящей дисІгипоциркуляции дистальных отделов кисти при контрольной УЗДГ БЦА и В. Иногда это происходит сразу, а иногда только после 3-5 сеансов МТ, допплерография регистрирует инволюцию степеней скаленус синдрома.

Развитие синдрома грушевидной мышцы (пириформис синдроме) (Рис 19) во многом сходно с развитием синдрома передней лестничной мышцы (съаленус синдроме). В обоих случаях основой патогенеза является патологическое напряжение мышцы, которая благодаря анатомическим особенностям, сдавливает (раздражает) седалищный нерв отчего страдает подвздошная артерия. Так же как и при скаленус синдроме исследование прово-

Синдром грушевндной мышшы

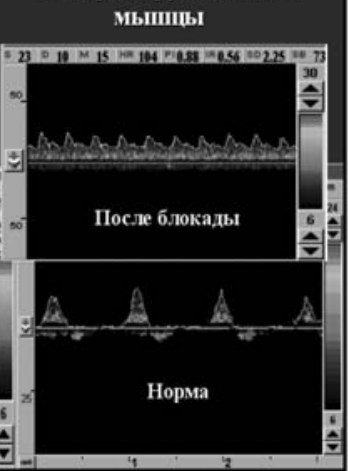

с. 20. Спектр артериолярног кровотока

низмов ведет к сходности допплерографической картины: если в норме форма спектра ЛСК по артериолам большого пальца стопы сходна со спектром передней тибиальной артерии (трехфазный или двухфазный спектр), или имеет монофазный спектр (у людей старше 50 лет), то на стороне пириформис синдрома спектр монофазный или абортивный, куполоподобный спектр (Рис 20). Сочетание отсутствия признаков облитерации артерий и вместе с тем наличие признаков выраженной артериолярной дисциркуляции на стороне болей характерно именно для пириформис синдрома.

При исследовании кровотока после лечения (при положительном эффекте после сеансов МТ, и|или после новокаиновой блокады грушевидной мышцы, что в комплексе дает быстрый и более стойкий эффект) можно регистрировать нарастание абсолютных показателей ЛСК и изменение формы спектра артериолярного кровотока (Рис 20). 


\section{Выводы:}

Система обеспечения вращения потока крови является универсальным механизмом, обеспечивающим кровообращение при минимальных энергетических затратах.

Существует анатомо-функциональные особенности строения и функционирования сосудистой системы, обеспечивающие защиту мозга от гидродинамических ударов и, одновременно, поддерживающие непрерывную перфузию крови через вещество мозга.

Вращение потока крови может быть оценено при помощи допплерографии.

Мануальная терапия на шейном отделе позвоночника активирует механизмы NO-активации кровотока в позвоночных артериях.

\section{ЛИТЕРАТУРА}

1. Асфандияров Р.И., Нефёдов А.Ю, Система обеспечения закрученных пото-ков крови на этапах онтогенеза человека., Доклад. Материалы №-го съезда гис-тологов, анатомов и эмбриологов, топохирургов. УССР., г. Черновцы с 24.

2. Нефёдов А.Ю., Ситель А.Б. Феномен пост манипуляционной гиперемии в вертебрально-базилярной системе. Переходные процессы при восстановлении кровотока в позвоночных артериях. Материалы первого съезда мануальных терапевтов России
Нарушение вегетативной регуляции сосудистого тонуса при синдроме передней лестничной мышцы и синдроме грушевидной мышцы являются причиной дисциркуляции в дистальных отделах конечностей.

Допплерография выявляет феномены патогномоничные для спондилогенных заболеваний и может применяться для диагностики и контроля эффективности лечения.

Таким образом, знание особенностей кровообращения, клинических проявлений, владение методами дополнительного обследования в клинике мануальной терапии позволяет не только проводить диагностику и лечение, но и находить новые методы исследования, не прибегая для этого к использованию дорогостоящего оборудования.

1999 г., М, МЗ РФ, с 28.

3. Нефедов А.Ю., В.О. Лесовой Допплерографический феномен нарушения микроциркуляции в дистальных отделах нижних конечностей при ятрогенном синдроме грушевидной мышцы., Материалы международной конференции «Актуальные проблемы биологии и медицины», Астрахань 2000, с 252.

4. Нефёдов А.Ю,, Ситель А.Б., Убрятов В.Б., Допплерографические феномены при скаленус синдроме., Материалы первого съезда мануальных терапевтов России 1999 г., М, МЗ РФ, с 32.

\title{
ARTERIYYLARDA QANIN NIZAMLI HӘRӘKӘTİ HAQDA
}

Nefyodov A.Yu., Asfandiyarov R.İ., Svetaylo L.Yu., Kanaev S.P., Rasstrigin S.N.

Rusiya Federasiyası Səhiyy Nazirliyinin Manual Terapiya Morkəzi, Moskva; Astraxan Dövlat Tibb Akademiyasının Insan anatomiyası Kafedrası, Astraxan

\section{ABOUT THE ORDERED ROTATION OF BLOOD IN ARTERIES}

\author{
Nefedov A.Yu., Asfandiyarov R.I., Svetaylo L.Yu., Kanaev S.P., Rasstrigin S.N. \\ Center of manual therapy of Ministry of health of Russian Federation, Moscow; \\ Astrakhan State Medical Academy, Department of human anatomy, Astrakhan, RF
}

Redaksiyaya daxil olub: 02.08.2012

Çapa tövsiya olunub: 30.08 .2012

Rayçi: R.L.Hasanov t.e.d.dos. 